\title{
«... EN TIEMPO MENOS DISCRETO QUE EL DE AGORA, AUNQUE DE HOMBRES MÁS SABIOS, SE LLAMABAN A LAS NOVELAS CUENTOS». LA NOVELA CORTA Y EL CUENTO EN EL SIGLO DE ORO ${ }^{1}$
}

\author{
María Jesús Zamora CALVo \\ Universidad Autónoma de Madrid \\ mariajesus.zamora@uam.es
}

$\mathrm{D}$ urante el Siglo de Oro español las diferencias entre la novela corta y el cuento no eran del todo claras, tanto es así que muchos autores incluso confundían la una con el otro, llamando cuento a lo que realmente era novela corta y viceversa. La obra narrativa de Cervantes ayudó a esclarecer este desconcierto, marcando el camino por el que discurrirían, a partir de entonces, estos géneros literarios. Por ello en este artículo nos proponemos realizar un repaso a la concepción que se tenía de estas narraciones en los siglos XVI y XVII, el origen etimológico de las mismas, cómo fueron utilizadas por los escritores de esa época, cómo surgió el desorden a la hora de nombrarlas y emplearlas, para terminar planteando los rasgos textuales que diferencian a estos dos géneros tan próximos como distantes en la literatura áurea hispánica.

Bajo el término novela, se acoge una gran diversidad de obras que pueden reunirse, por el tema o por la forma, en grupos cuyos elementos comunes son escasos, tanto es así que al hacer un examen general de todos ellos da la impresión de que el nexo de unión tan solo sea la prosa. Estamos por lo tanto ante una de las manifestaciones más complejas y amorfas de la literatura (Muir 1967), lo que dificulta formular una definición clara y completa de este género. No obstante, si ahondamos en su descripción, descubrimos que cualquier texto clasificado con esta denominación se caracteriza por disponer de un discurso en prosa polifónico,

1 Este estudio se ha realizado en el marco del Grupo de Investigación «Mentalidades mágicas y discursos antisupersticiosos (siglos XVI, XVII y XVIII)», reconocido oficialmente en la Universidad Autónoma de Madrid con el código F-081. 
por contar con un narrador que organiza no solo la historia en un argumento, sino también sus voces, a la vez que sirve de centro para las relaciones y las referencias textuales. Además, las novelas están construidas a partir del correcto entramado entre los personajes, las acciones (situaciones humanas) y el cronotopo (tiempo y espacio) (Baquero 1993, Blasco 1998, Bobes 1998, Bourneuf 1983, Delgado 1973, Durán 1976: 55-91, Forster 1983, Fradejas 1985, Hurtado 1983, Menéndez Pelayo 1961, Palomo 1976, Prieto 1975 y Tacca 1975).

Sobre su origen, desde un punto de vista etimológico la voz novela procede del italiano novella ${ }^{2}$. En el caso concreto de España se creía que había sido importada por el traductor del Decamerón de Boccacio, pero hay textos más antiguos donde ya aparece:

El Marqués de Santillana empleó ya [...] la voz novella en la estrofa XLIV de su Comedieta de Ponza, en un pasaje al que, bien interpretado, cabe dar a esta significación literaria: "Fablavan novellas, e contaban cuentos” (Obras, edic. de J. Amador de los Ríos, Madrid, 1852, p. 115). Luego Nebrija en su Vocabulario español latino... ¿Salamanca, 1495? (Sign. K-I), registra las voces Novela o conseja para contar. Novelas, contar (fabulor, aris), y Novelero, contador de novelas, Fabulator. Viene después otra cita de la voz novela en los Inventarios reales de 1503 (vid. J. FeRRANDIS: Datos documentales para la Historia del Arte español, III, Madrid, 1943, pp. 153 y 158), con la clara acepción moderna literaria: a la que sigue el Cancionero General de Hernando del Castillo, Madrid, 1878 (tomo II-18, edic. Bibliófilos Españoles), con el empleo de la voz novela, equivalente a patraña, embuste, cosa dudosa o inverosímil, acepción que conservará todavía durante bastantes años del siglo xVI, con FeRNÁNDEZ DE Oviedo en su Historia general y natural de las Indias... Sevilla, 1553 (tomo I, p. 13 de la edición académica de Madrid, J. Rodríguez, 1851-1855), Timoneda en su Patrañuelo... Valencia, 1566, y GarCiLAso en sus Comentarios reales, para llegar hasta el xvir con Vicente Espinel en sus Relaciones del Escudero Marcos de Obregón, Madrid, 1618, prólogo (fol. VII de sus Preliminares). Cervantes a su vez empleó también la voz novela en la acepción de obra de entretenimiento, no breve, sino extensa, como el roman francés. [...] Al incorporarse la palabra italiana novella a nuestro lenguaje castellano en el siglo $\mathrm{xv}$, tuvo en un principio dos formas morfológicas vacilantes, pues tan pronto se escribía novella como novela (Amezúa y Mayo 1982: t. 1, 351).

Conviene recordar que la utilización que Cervantes hace de este término no coincide exactamente con lo que en la actualidad designamos como novela. Según Javier Blasco, es un género nuevo nacido para demostrar si son factibles o no las teorías esbozadas por los preceptistas en relación con la narración en prosa:

En italiano novella es un diminutivo formado a partir del latín nova y significa 'novedad', 'pequeña historia', 'noticia de un suceso más o menos reciente' (Bolelli 1985: 1128). 
Cervantes $[. .$.$] hace confluir en su discurso todas las propuestas de su época. Las$ superpone, las somete a crítica, obteniendo como resultado, una narración que puede leerse, a la vez, como cómica epopeya y como parodia del relato histórico. Si esto es así, el Quijote surge de los esfuerzos que hace un narrador por dar solución, desde la práctica de la escritura, al dilema teórico (la problemática relación entre la verdad universal de la poesía y la verdad concreta de la historia) más grave que la crítica de su tiempo tenía planteado, así como a la necesidad de hallar acomodo, entre una y otra (poesía e historia), a un género más acorde con los gustos y exigencias del lector moderno (1998: 69).

Cervantes cae en la cuenta de que la historia enseña sin deleitar, mientras que la ficción plasmada en los libros de caballerías deleita sin enseñar. Reconoce que el discurso que mejor puede suplir las necesidades narrativas de su momento histórico es aquel en el que se enseñe deleitando, es decir, que instruya como la historia y que agrade como la ficción. Este tipo de narración es la que lleva a su consecución en el Quijote donde, por un lado, respeta la verosimilitud exigida por la preceptiva aristotélica y, por otro, refleja su experiencia de lector y de escritor. Frente a la teoría verbalizada por los personajes opone la realidad literaria de la época, dando lugar por lo tanto a una metanovela, «la novela que trata de cómo se escribe una novela», pero también, «la novela que trata de cómo se lee una novela» (Blasco 1998: 85).

Históricamente este género se vincula con la epopeya ${ }^{3}$. Autores como Kristeva (1974) y Bajtín (1991), entre otros, consideran que dicho nexo de unión se produce con respecto a la forma, la novela cambia el verso por la prosa y no introduce en un principio alteraciones en el contenido relatado. Pero destacan cambios sensibles en el tratamiento del tiempo, en la concepción y la presentación de los personajes, en la ideología y la visión del mundo que sirve de marco de referencia y que explica las formas de narración. Por ello tenemos que los rasgos generales que caracterizan a la novela moderna en oposición a los de la epopeya son: temática reducida a la de un mundo visto de forma parcial, individualizado; la elección de temas de la vida ordinaria; la temporalidad situada en el presente y con ambiente contemporáneo; la presencia de personajes sin grandeza, que viven problemas semejantes a los que pueda tener cualquiera

3 «Como precedente de las novelas [...], considera Bajtín que hay ya en la época clásica “embriones” de prosa bivocal y bilingüe que, si bien no pueden considerarse novelas, son el origen de su material y su técnica: sátiras, formas autobiográficas o biográficas, etc., que dieron lugar de inmediato a modelos simplificados de novela como la Novela del asno, la del pseudo Luciano y la de Apuleyo, y el Satiricón, de Petronio. [...] A una línea estilística diferente pertenecen las llamadas "novelas sofísticas", como la de Aquiles Tacio, Leucipo y Clitofonte, que son novelas convencionales detrás de las cuales no hay un sistema ideológico único, importante y sólido, de tipo religioso, político-social, filosófico, ni hay tampoco unidad de estilo» (Bobes 1998: 79).

Edad de Oro, XXXIII (2014), pp. 109-124, ISSN: 0212-0429 
de los lectores y a los que se somete a pruebas necesarias para mostrar el sistema de valores que se constituye como eje de su conducta; la carencia de toda trascendencia religiosa.

Francisco Ayala (1971), por su parte, explica estos cambios a causa de la disposición de las categorías narrativas que se dan en el paso de la epopeya a la novela, basándose para ello en una visión diferente del mundo, la medieval y la renacentista, que da sentido a los poemas épicos y a las novelas respectivamente. «La mayor parte de los teóricos e historiadores de la literatura están de acuerdo en que la aparición de la novela se produce en el paso de la Edad Media al Renacimiento, con el florecimiento de las ciudades y con el cambio de vida que supone para el hombre urbano pasar de una sociedad gremial a una sociedad industrial» (Bobes 1998: 62). Según Ayala, el hombre renacentista necesita contestar a una serie de preguntas sobre su existencia a las que la cultura medieval respondía por medio de la fe. Esas explicaciones nuevas se concretan en modelos de vida y de conducta a través de las historias que presentan las novelas, vividas por unos personajes que también actúan como modelos humanos.

Frente a estas tesis que vinculan la novela con la épica y que explican el cambio a partir de una evolución social o formal, otras teorías relacionan la novela con el cuento. Ambos géneros literarios se diferencian por rasgos que van mucho más allá de la mera extensión textual. El cuento se centra más en la acción, en instantes precisos en la vida, mientras que la novela construida por la unión de varios cuentos utiliza como elemento coordinador la trayectoria del aprendizaje de una persona: el protagonista. De este modo, la narración novelesca no es la suma de distintas cuestiones, sino la articulación de todas en una lectura común encauzada hacia un sentido final.

En cuanto al término cuento, su origen procede, según el Diccionario etimológico de Joan Corominas (1954: t. 1, 888), del verbo latino computare, con el sentido de 'calcular, computar'. De esta acepción pasa a significar 'relatar historias', al enumerar en lugar de objetos, acontecimientos. Dicha evolución semántica queda ya perfectamente documentada en el Disciplina Clericalis de Pedro Alfonso, donde se incluye un relato en el que, para conciliar el sueño, un rey pide a uno de sus súbditos que le cuente algún suceso ameno y entretenido. Este empieza con la historia de un aldeano que se ve obligado a pasar dos mil ovejas de una a otra orilla del río, utilizando para ello una barca donde solo caben dos animales. Ante esta situación, el siervo aconseja al rey que se entretenga enumerándolas. Recoge, en definitiva, el conocido tópico de contar ovejas para provocar el sueño. A este respecto, Mariano Baquero Goyanes considera que no existe «en toda la historia del género [...] un ejemplo tan expresivo como éste de Pedro Alfonso, tan revelador de cómo un mismo étimo latino se bifurcó en un doblete: cómputo-cuento (un cultismo y una voz popular, la primera de las cuales quedó reservada para lo 
estrictamente numérico, en tanto que la segunda se vinculó al viejísimo quehacer humano de narrar hechos e historias curiosas)». (Baquero 1993: 100)

Durante la Edad Media parece ser que nunca se utiliza el término cuento para referirse a una narración breve. Se prefiere denominarlas como fábulas, fabliellas, exiemplos, apólogos, proverbios, castigos, etc., tal y como queda documentado en el Calila e Dimna:

Et posieron enxemplos et semejanças en la arte que alcançaron et llegaron por alongamiento de nuestras vidas et por largos pensamientos et por largo estudio; et demandaron cosas para sacar de aquí lo que quisieron con palabras apuestas et con razones sanas et firmes; et posieron et conpararon los más destos enxenplos a las bestias salvajes et a las aves (1984: 89).

Don Juan Manuel utiliza el término fabliellas en el Libro del Caballero y del Escudero (1955: 7), al mismo tiempo que emplea exemplo para designar las narraciones incluidas en El Conde Lucanor. En el Libro de Buen Amor, Juan Ruiz, arcipreste de Hita, se sirve de palabras como: proverbio, fabla, estoria, etc., para denominar a este tipo de relatos, términos estos que vuelven a ser empleados en otras colecciones de cuentos medievales como: el Libro de los exemplos por A.B.C. de Clemente Sánchez Vercial, el Libro de los gatos (mala lectura de Libro de los quentos) o el Libro contra engaños y peligros del mundo.

A comienzos del siglo Xvi, la incorporación de la palabra italiana novella al léxico castellano como 'novela' origina una cierta confusión, ya que hace referencia a los mismos relatos breves englobados bajo la etimología de cuento. De ahí que Lope de Vega en Las fortunas de Diana aclare que «... en tiempo menos discreto que el de agora, aunque de hombres más sabios, se llamaban a las novelas cuentos. Éstos se sabían de memoria, y nunca que me acuerdo, los vi escritos» (1968: 27). El mismo Mateo Alemán, uno de los precursores de la novela moderna, al describir la vida humilde de los pajes en su Guzmán de Alfarache, pone en boca de uno de ellos estas palabras: «Leíamos libros, contábamos novelas» (1987: t. 1, 456).

Preceptistas como Juan de Valdés ${ }^{4}$ y escritores como Suárez Figueroa ${ }^{5}$ hacen claro manifiesto de su repulsa hacia el neologismo italiano novella, propugnando la voz castellana de cuento como más apropiada. Incluso Miguel de Cervantes en

4 «También cuento es equívoco; porque dezimos cuento de lança y cuento de maravedís y cuento por novela» (1972: 161).

5 «¿Acaso gustáis de novelas al uso?», pregunta uno de los interlocutores de El Pasajero, a lo que contesta don Luis: «No entiendo ese término, si bien a todas tengo poca inclinación, por carecer de versos». Y entonces el mismo Suárez Figueroa declara su juicio adverso a las novelas y el nulo valor literario que se las daba, como tantos otros de su tiempo: «Por novelas al uso entiendo ciertas patrañas y consejas, propias de brasero en tiempo de frío, que en suma viene a ser unas bien compuestas fábulas, unas artificiosas mentiras» (1618: f. 56).

Edad de Oro, XXXIII (2014), pp. 109-124, ISSN: 0212-0429 
la «Dedicatoria» a sus Novelas ejemplares, las llama cuentos: «Solo suplico que advierta Vuestra Excelencia que le envío, como quien no dice nada, doce cuentos...» (1995: t. 1, 54). Para Gracián no son más que «cuentos que van heredando los niños de las viejas» (Chevalier 1999: 13). Y todavía a mediados del siglo XVII, cuando Saavedra Fajardo, en su República literaria, enumera a los cultivadores de las letras que la componen, como poetas, filósofos, historiadores, juristas, matemáticos, médicos, astrólogos, etc., ni incluye en ella a los novelistas, ni cita una sola novela ni cuento.

Todos estos testimonios nos revelan que durante el Siglo de Oro se conocen los cuentos tradicionales, pero hacia ellos se muestra bastante desprecio. En esta época, el término cuento se asocia a la narración oral, por lo que queda en un principio vinculado a una determinada persona que no solo ha de recordar el contenido de las historias, sino que también debe tener la gracia y el acierto verbal a la hora de exponerlas en público. Mientras que el vocablo novela se reserva a los relatos breves escritos.

Así en el Quijote observamos cómo las historias que aparecen narradas por algún personaje - por ejemplo, la de Grisóstomo y Marcela, contada por el cabrero Pedro- reciben el nombre de 'cuentos': «Donde se da fin al cuento de la pastora Marcela con otros sucesos» (capítulo XIII de la 1 parte). Por el contrario, El curioso impertinente es presentada como novela por tratarse de una narración escrita. El cura halla unos papeles en la maleta que le enseña Juan Palomeque, el ventero: «Sacoles el huésped, y dándoselos a leer, vio hasta obra de ocho pliegos escritos de mano, y al principio tenían un título grande que decía: Novela del curioso impertinente» (Baquero 1993: 103).

Pese a ello, los cuentos tradicionales tienen una gran influencia sobre los escritores de los siglos XVI y XVII. Los genios artísticos que surgen en esta época recrean y transfiguran este material extraído de la tradición a través de narraciones breves transmitidas tanto de forma oral como escrita, dando lugar a creaciones literarias que llegan incluso a sentar las bases de la narrativa moderna. Un claro ejemplo nos lo muestra de nuevo Miguel de Cervantes, quien toma una variante del cuento tradicional de La hija del diablo, para documentar la historia del capitán cautivo. Maxime Chevalier se ha encargado de estudiar minuciosamente el trabajo realizado por Cervantes, a este respecto:

Debió Cervantes situar la acción en un espacio concreto, anclar la ficción en el tiempo presente, apartándola de un pasado más o menos borroso, individualizar a los personajes genéricos del cuento, desechando los estereotipos de la tradición oral, hacer que los personajes se configuraran progresivamente según progresara la acción, escribir por fin un texto dándole el toque que únicamente confiere la mano del escritor (Chevalier 1999: 13). 
Al llegar a este punto debemos precisar que los grandes ingenios renacentistas y barrocos desconocen el valor que este tipo de relatos tiene. No saben lo que es un cuento tradicional. Tampoco perciben las huellas que dejaron en los textos de la Antigüedad Clásica. A ninguno se le ocurre sugerir que realmente existe un vínculo muy estrecho entre las consejas y los chistes que cuentan las viejas y las obras tan admiradas, estudiadas y seguidas de autores como Herodoto, Horacio o Tito Livio. En definitiva, ignoran que se trata de una narración cuyas raíces se pierden en la historia de la humanidad.

Este desconocimiento no impide que consciente e inconscientemente los cuentos tradicionales invadan la literatura europea de los siglos XVI y XVII, ya que es en ese momento cuando son apreciados como relatos de puro entretenimiento, desapareciendo la función exclusivamente didáctica que se impuso durante la Edad Media $^{6}$. En el caso español, autores de diálogos como Luis Milán, Cristóbal de Villalón, Pero Mexía y el mismo Juan de Valdés, quien había hecho claro manifiesto de su desprecio hacia estas narraciones, las insertan en libros que están dirigidos a la meditación del público culto, con lo que se logra una difusión de la tradición cuentística en esta época.

Estos relatos aparecen primero en los refraneros, cuyos autores, entre los que destacamos a Luis Galindo, Hernán Núñez, Juan de Mal Lara, Sebastián de Horozco y Gonzalo Correas, copian gran cantidad de cuentos para aclarar tanto refranes como frases proverbiales. Posteriormente lexicógrafos como Sánchez de la Ballesta y Covarrubias, se hacen eco de estos textos en sus definiciones. Al igual que aparecen en algunos pliegos sueltos del siglo xvI, tal y como ha reproducido Alan C. Soons en su estudio Haz y envés del cuento risible en el Siglo de Oro (1976). Los autores de misceláneas —el fraile dominico escritor de Floreto de anécdotas, el de Glosas al sermón del Aljubarrota o Luis Zapata- también incluyen algún cuento en sus obras. Muy numerosos son los relatos breves recogidos en entremeses, comedias y novelas en esta época (Chevalier 1978).

Volviendo a la novela, desde el punto de vista cultural, esta se inicia en España con la Celestina (Guillén 1988), pero formalmente nace con el Lazarillo, obra que reúne varios cuentos tradicionales mediante la técnica d'enfilage: el hilo conductor es la vida de un personaje, Lázaro de Tormes. Esta técnica se toma, según algunos críticos (Rico 1988 y Artaza 1989), de las formas de otros discursos, de manera especial el judicial, que se adaptan a la expresión literaria.

Se podría hablar en el Lazarillo, como en cualquier obra que se proponga demostrar una tesis o enseñar, de cierto carácter deliberativo: persuadir de la influencia de la fortuna y de la educación en la conducta del individuo, aunque el autor, a

$6 \quad$ Esta afirmación es respaldada por la gran cantidad de colecciones que surgen durante los siglos XVI y XVII, destacando entre todas ellas las de Juan de Timoneda, Luis de Pinedo, Melchor de Santa Cruz y los recopiladores de los llamados Cuentos de Juan de Arguijo. 
diferencia del orador político, no persiga arrancar una decisión concreta y práctica en el lector, en definitiva, si enfocamos la novela desde el ángulo retórico, esta se convierte en un pliego de descargos, en una narratio de defensa del caso en la que se observan escrupulosamente los principales preceptos (Artaza 1989: 279-281).

En el paso del cuento a la novela, la importancia del Lazarillo no reside del todo en la estructura de la obra, sino en el fin pragmático que persigue, intentando dar respuesta a las preguntas sobre distintas conductas del hombre, sobre algunas situaciones que pueden parecer extrañas, sobre diversas cuestiones acerca de la naturaleza humana. Lázaro, al final de su vida, es un cínico que enfoca su existencia de acuerdo con lo que ha captado a lo largo de sus fortunas y adversidades, tal como él mismo explica en el prólogo. La novela puede ser ejemplo positivo o negativo de cómo se aprende a vivir mediante la experiencia en fases.

Desde su nacimiento la novela es la depositaria de los conflictos del hombre. La abundancia de códigos, normas y esquemas constituye un laberinto de ideas donde el lector del relato es obligado a buscar su norte:

[...] las preguntas, las dudas, los planteamientos inconclusos abundan y se multiplican en la mente del lector de la obra cervantina, mientras que las preguntas escasean o quedan largo tiempo aplazadas. Bien claro está que el ademán interrogativo del lector refleja el de los personajes de un libro cuya contextura envuelve tanto diálogo, tanto signo enigmático, tanto proceso abierto de conocimiento [...]. El autor sitúa en el centro de la acción no tanto unas realidades como el esfuerzo de unos hombres para descifrarlas. Lo que sucede es ese intento de averiguación, ese afán de unos hombres por conocerse y aprenderse los unos a los otros (Guillén 1988: 212).

Una perspectiva nueva sobre el origen de la novela nos la da Mijail Bajtín. Para él este género queda definido por su plurilingüismo o dialogismo, rasgo del discurso que quedó perfectamente implantado por Miguel de Cervantes. La novela moderna nace y se desarrolla en un proceso de interacción lingüística libre sobre obras y sobre lenguajes diversos: «la palabra ennoblecida en relación con el plurilingüismo aparece en Don Quijote en los diálogos novelescos con Sancho y otros representantes de la realidad plurilingüe y grosera de la vida» (Bajtín 1991: 199).

Resulta peculiar que desde cualquier perspectiva se llegue a la conclusión de que es Cervantes el padre de la novela moderna, tanto si se tienen en cuenta las tesis de Ayala y de Guillén, o si se centra en las teorías culturalistas sobre el antropocentrismo renacentista, la relativización de las opiniones, la forma del discurso y su plurilingüismo, etc., siempre Cervantes está en el inicio.

También con el cuento, Cervantes recrea y transfigura el material narrativo que le proporcionan estas narraciones, insertándolo a lo largo de novelas como 
el Persiles, que aparece plagado de anécdotas tan conocidas y difundidas entre la gente que pertenecen ya a su acervo cultural. Su mismo comienzo nos evoca el caso de Ifigenia, que aparece recogido en Philosophia antigua poetica (1596) de Alonso López Pinciano, obra que seguro conoce nuestro autor:

Siendo vna doncella a punto de ser degollada en sacrificio, fue desaparecida de aquellos que la querian sacrificar y lleuada a vna region remota a ser sacerdotissa, en la qual region era costumbre sacrificar los estrangeros que alli aportauan. Sucedio, pues, que despues de algunos dias arribo a aquella tierra vn hermano de la donzella sacerdotissa, el qual fue presso y lleuado, segun la costumbre que alli auia, a que fuesse sacrificado por mano de la hermana, que fue causa de la saluacion del hermano. Este es el argumento y propio de la fabula de la Iphigenia (1953: 18-19).

Lo mismo ocurre con el suceso que marca la vida de Antonio 'el bárbaro', por el que se ve obligado a abandonar su hogar, sufrir diversas peripecias, hasta recalar en la Isla Bárbara (I, 5). Este asunto está tomado, tal y como demuestra Juan Bautista Avalle-Arce (1975: 75-82), del Examen de ingenios de Huarte de San Juan (1989: 556-557), quien a su vez lo debe adquirir de la cantera popular, ya que poco antes, Melchor de Santa Cruz en su Floresta española recoge el siguiente cuento:

Un estudiante, preciándose de muy privado de una señora, fuela a visitar con otro. Y ella llamábale vos, y él llamola señoría. La señora, muy enojada, le preguntó por qué la llamaba señoría. Respondió el estudiante: «Suba vuestra merced un punto, y abajaré yo otro, y andará la música concertada» (1996: 313-314).

Otra de las primeras narraciones insertas en el Persiles, la del portugués Manuel de Sousa Coutiño, hay que relacionarla con la de Ricaredo e Isabela en La española inglesa (1995: t.1, 241-283). En ambas, el amante (Ricaredo-Manuel) se ve forzado a separarse de su amada (Isabela-Leonora), pero se establece un plazo de dos años antes de que la prometida pueda tomar otra decisión. Justo el mismo día en el que se cumple dicho plazo, Isabela-Leonora está a punto de jurar los votos como monja. En ese momento aparece el amante, dando como resultado que, en el caso de Isabela, esta se decante por el amor humano, mientras que Leonora, opte por el divino.

Una de tantas consejas que le llegan a Cervantes de Olao Magno o de Torquemada es la del pájaro barnaclas (I, 12). Casi todos los autores que mencionan a dicho animal lo localizan en Hibernia, como sinónimo de Irlanda. Sin embargo, no falta quien afirma que el lugar preferido por estos animales sean las Horcadas, Escocia, Inglaterra o las Hébridas (Romero 2002: 719-720). Pero lo más importante en este caso es que, al incluirlo en el Persiles, su autor quiere 
poner de manifiesto no solo su origen tradicional, sino también las fuentes que utiliza para respaldar sus historias. De este modo, esta narración deja de ser una digresión imaginativa para convertirse en otra instructiva.

Con respecto al cuento donde se nos relata el ius primae noctis (I, 12), Carlos Romero considera que su fuente pertenece al 'Inca' Garcilaso; aunque también puede proceder del Omnium gentium mores leges et ritus ex multis clarissimis rerum scriptoribus de Juan Bohemo (1520) (Romero 2002: 720-721).

A la hora de insertar estas historias dentro del Persiles, Cervantes opta por emplear una técnica muy sencilla y que repite en cada uno de los casos: alguien aparece en el momento más pertinente, cuenta su vida o el fragmento más notable de la misma y pasa a formar parte de un grupo en constante incremento, que se desplaza de un lugar a otro, hasta que el autor halla la manera de dejar por el camino a los más innecesarios. Mediante este procedimiento, Cervantes nos ofrece en este libro una visión compleja y variada de distintas realidades, que ambientan la novela a través de la diversidad de los puntos de vista que ofrecen los sujetos narradores.

Cervantes toma este esquema narrativo de La Diana de Jorge de Montemayor: a partir de un marco determinado se ensartan diversas historias, pero no una tras otra, sino que, de hecho, aparecen entrelazadas (López Estrada 1954: LxxxILXxxII, Avalle-Arce 1959: 92, Johnson 1971: 20-35, Keightley 1975: 194-219, Prieto 1975: 348, Rallo 1991: 51, Montero 1996: xxvII-XciI y Sánchez Jiménez 2012: 23-36). Este patrón bizantino es el que permite a Cervantes llevar una serie de historias arracimadas hacia una conclusión final, disponiendo a la vez de un amplio margen para inserciones y suspensiones narrativas. Con ello consigue dar una gran variedad expositiva al Persiles.

La presencia de dichos personajes varía entre la primera y la segunda parte. Si inicialmente su número es reducido, aunque la duración de sus historias se prolongue, en la siguiente, la cantidad de actantes es más cuantiosa, pero, en compensación, se limita la extensión de sus narraciones. El cambio es tan considerable que incluso Jean Babelon define esta segunda parte como un «Decamerón itinerante» (Babelon 1947: 117), en el sentido de que el viaje de los protagonistas se constituye como mero marco de otras historias. Esta forma de enfocar la narración tiene un reflejo directo en la manera de introducir los capítulos: si en los dos primeros libros la exposición es más fluida, armoniosa y equivalente, en el tercero cada capítulo constituye una única unidad donde una historia menor comienza y concluye de manera creíble.

La temática de estos cuentos gira generalmente en torno al amor. Desde la lascivia de Rutilio y Clodio hasta la senilidad de Policarpo, sin obviar la cobardía de Feliciana, Cervantes nos muestra diversos efectos provocados por una pasión amorosa que no ha sido controlada por la razón y que se deja en las manos del 
libre albedrío, la locura, el instinto, la inexperiencia, la inmadurez o incluso la supervivencia innata del individuo; todo lo contrario de lo que ocurre al dominio ejemplar que tienen de sus sentimientos Periandro y Auristela —Blecua (1985: 147), Egido (1991: 201-224) y El Saffar (1990: 17-33)—. Otras historias son más complejas, como la de Antonio 'el bárbaro' (I, 5), donde la altanería y el orgullo llegan a eclipsar el rasgo más característico del español de esta época: la honradez (Herrero García 1966). En contraposición a este relato se encuentra el de Transilia (I, 12 y 13), quien defiende su virginidad con vehemencia y rechaza aquellas leyes que van en contra de la dignidad humana.

En este tipo de cuentos, lo real y lo mágico no constituyen dos categorías lógicas. Los personajes no temen a lo sobrenatural ni a los seres del más allá en cuanto a tales. El mundo está poblado de hechiceras, licántropos, magos, astrólogos, animales fabulosos, demonios y diablillos. Sin embargo, nunca aparecen descritos como seres fantásticos; el narrador se limita a hacerlos actuar: intervienen solos, son capaces de sufrir metamorfosis, adivinan lo que va a ocurrir; son inconcebibles en nuestra realidad, pero completamente admisibles en el Siglo de Oro, como se comprueba en el siguiente fragmento:

Y, diciendo esto, comenzó a abrazarme no muy honestamente. Apartela de mí con los brazos, y, como mejor pude, divisé que la que me abrazaba era una figura de lobo, cuya visión me heló el alma, me turbó los sentidos y dio con mi mucho ánimo al través. Pero, como suele acontecer que en los grandes peligros la poca esperanza de vencerlos saca del ánimo desesperadas fuerzas, las pocas mías me pusieron en la mano un cuchillo, que acaso en el seno traía, y con furia y rabia se le hinqué por el pecho a la que pensé ser loba, la cual, cayendo en el suelo, perdió aquella fea figura, y hallé muerta y corriendo sangre a la desventurada encantadora (I, 8).

Como acertadamente afirma Max Luthi, en el momento en que se funde lo natural y lo extraordinario, tan solo tiene cabida ya una única dimensión espacial, en la que «la magia, que desempeña importante papel en el cuento, no necesita explicación artificial, pues el hombre de otros tiempos ha vivido diariamente lo maravilloso» (1947: 11-17).

Una parte de estos cuentos queda marcada por elementos, rasgos, caracteres, etc., procedentes de la realidad cotidiana que les circunda, en el momento concreto en que son verbalizados. De este contexto toman conductas y relaciones, salpicadas por pequeñas dosis de picardía, erotismo, superstición, etc. En ellos se refleja el reverso de los valores positivos, suelen ser sustituidos por el ingenio, la astucia, la prudencia, la desconfianza, la insolidaridad, etc., de la que hace gala el protagonista de cada relato para engañar a sus opresores, salir de situaciones difíciles, eludir persecuciones o castigos, muchas veces injustificados en el mismo 
texto y que remiten a situaciones paralelas de la vida real, con las que posiblemente se identifiquen los lectores de los mismos ${ }^{7}$.

De ahí que en la segunda parte del Persiles localizamos a un buen puñado de personajes que poco o nada tienen de heroicos, como Bartolomé, especie de Sancho Panza cegado por la pasión amorosa (III, 11); los alcaldes villanos, muy cercanos a los actantes que salpican los entremeses de la época (III, 10); los falsos cautivos, que constituyen una auténtica plaga social del siglo Xvi español, siendo tomados ya como tipos literarios (III, 10); el episodio morisco, reflejo de la dura situación que soportaron este grupo en la península (III, 11), etc.

Pese a la confusión que durante el Siglo de Oro existió entre el cuento y la novela, Cervantes se preocupa por diferenciarlos y dignificar unos relatos considerados más propios de viejas ignorantes que de intelectuales eruditos. Con respecto a la técnica que emplea para insertar estos relatos en la trama principal de la obra, descubrimos que es muy semejante a la utilizada por Jorge de Montemayor en La Diana. De esta manera, en el Persiles, en un momento determinado del viaje, aparece un personaje que cuenta su vida, pasando a formar parte del grupo de viajeros. Mientras que en la primera parte el número de estos personajes es más bien reducido y la extensión de sus relatos bastante larga, en la segunda, su cantidad aumenta y las historias de sus vidas se exponen de forma mucho más abreviada.

Al llegar a este punto podemos ya esbozar las diferencias existentes entre la novela corta y el cuento en el Siglo de Oro español, géneros literarios que, como hemos visto, están muy vinculados tanto histórica como tradicionalmente. En primer lugar, cometeríamos una gran equivocación al considerar el cuento como una novela reducida, o a la novela como un cuento estirado. «Si de una narración breve sacamos la impresión de que allí hay en potencia una gran novela, es muy probable que estemos ante un mal cuento, ante una novela frustrada» (Baquero 1993: 130). Todo escritor, si es bueno, sabe captar la adecuación entre el tema que se quiere tratar y la forma con la que es mejor expresarlo, de ahí que nunca elegirá un asunto de novela para cuento o viceversa. La emoción estética proporcionada por ambas narraciones es muy diferente. Así, en el cuento, la nota sensible es única y emitida de una sola vez; es por lo tanto indivisible.

El origen de este tipo de relatos humorísticos se encuentra en las fábulas milesias de la época helenística. Disponen también de su correspondiente forma culta en obras como el Decamerón. Pueden explicarse en relación «con el juego, con la comicidad y con gustos que siempre han llevado al hombre a situar en contrapunto lo heroico y lo tosco, la valentía y la cobardía, el sacrificio y el amor a la buena vida, la verdad y la mentira ingeniosa, etc. Tiene también una amplia tradición en la cultura de Occidente, tanto en sus versiones populares, como en las colecciones cultas, y alternan con cuentos heroicos y de otros tipos en colecciones de todos los tiempos. Bajtín ha estudiado la risa y la parodia como constantes culturales presentes en las narraciones de todos los pueblos y de todos los tiempos» (Bobes 1998: 46-47). 
De una novela se evocan situaciones, descripciones y ambientes, pero no siempre el argumento. Sin embargo, un cuento se recuerda íntegramente o no se recuerda. En el cuento los tres tiempos - exposición, nudo y desenlace- de las viejas preceptivas están tan juntos que casi son uno solo. Ha de atrapar la atención del lector desde las primeras líneas. Una mejor diferenciación de la novela y del cuento podría hacerse a partir del distinto manejo que en uno y otro género se tiene de elementos aparentemente comunes como los personajes, los diálogos, las descripciones de paisajes y ambientes, etc. Debemos resaltar el carácter unitario y compacto del cuento, en contraste con el que la novela ofrece, al constar este último de una mayor variedad y matización en los episodios o partes que puedan componerla. La novela se caracteriza por su morosidad, por la relativa independencia de sus partes, dada por la variedad de episodios y de personajes. Siguiendo la opinión de Henri Mérimée:

[...] la novela persigue la aventura de que se trata desde sus orígenes a sus últimas consecuencias, es, en muchos aspectos, una "crónica", es decir, un relato cronológico cuyo plano se modela sobre el orden mismo de los acontecimientos y cuya exactitud no admite omisiones ni reducciones. El cuento y la novela corta buscan sus temas entre aquellos cuyas crisis, por su rapidez, exigen la brevedad; simplifican, condensan, proceden por omisión más bien que por desarrollo, proyectan su luz sobre algunas circunstancias de una situación, no constituyen ningún gran cuadro, sino una miniatura exactamente dibujada (Baquero 1993: 131-132).

Recibido: 2/09/2014

Aceptado: 15/10/2014

\section{OBRAS CITADAS}

Alemán, Mateo (1987). Guzmán de Alfarache. José María Micó (ed.). Madrid: Cátedra. Amezúa y Mayo, Agustín G. de (1982). Cervantes creador de la novela corta española. Madrid: CSIC.

ArTAZA, Elena (1989). El “ars narrandi” en el siglo XVI español. Bilbao: Universidad de Deusto.

Avalle-Arce, Juan Bautista (1959). La novela pastoril española. Madrid: Revista de Occidente.

(1975). «Tres vidas del Persiles». Nuevos deslindes cervantinos. Barcelona: Ariel, pp. 75-82.

Ayala, Francisco (1971). Teoría y crítica literaria. Madrid: Aguilar.

BABelon, Jean (1947). «Cervantes y lo maravilloso nórdico». Miguel de Cervantes Saavedra. Homenaje de «Ínsula» en el cuarto centenario de su nacimiento. Madrid, pp. 117-130. 
Battín, Mijail (1991). Teoría y estética de la novela. Trabajos de investigación. Helena S. Kriúkova y Vicente Cazcarra (trad.). Madrid: Taurus.

Baquero Goyanes, Mariano (1993). ¿Qué es la novela? ¿Qué es el cuento? Murcia: Universidad de Murcia.

Blasco, Javier (1998). Cervantes, raro inventor. Guanajuato: Universidad de Guanajuato.

Blecua, Alberto (1985). «Cervantes y la retórica [Persiles, III, 17]». En Lecciones cervantinas. Zaragoza: Caja de Ahorros y Monte de Piedad de Zaragoza, pp. 131-147.

Bobes Naves, María del Carmen (1998). La novela. Madrid: Editorial Síntesis.

Bolelli, Tristano (1989). Dizionario etimologico della Lingua Italiana. Milán: TEA.

Bourneuf, Roland y Réal Ouellet (1983). La novela. Enric Sullà (trad.). Barcelona: Ariel.

Calila e Dimna (1984). Juan Manuel Cacho Blecua y María Jesús Lacarra (eds.). Madrid: Clásicos Castalia.

Cervantes, Miguel de (1995). Novelas ejemplares. Harry Sieber (ed.). Madrid: Cátedra. (2002). Los trabajos de Persiles y Sigismunda. Carlos Romero Muñoz (ed.). Madrid: Cátedra.

Chevalier, Maxime (1978). Folklore y literatura. El cuento oral en el Siglo de Oro. Barcelona: Crítica.

(1999). «Ensayo preliminar». Cuento y novela corta en España. María Jesús Lacarra (ed.). Barcelona: Crítica, pp. 9-24.

Corominas, Joan (1954). Diccionario crítico etimológico de la lengua castellana. Madrid: Gredos.

Delgado León, Feliciano (1973). Técnica del relato y modos de novelar. Sevilla: Universidad de Sevilla.

DurÁn, Antonio (1976). «Teoría y práctica de la novela española durante el Siglo de Oro». Teoría de la novela. Madrid: SGEL, pp. 55-91.

EgIDo, Aurora (1991). «El Persiles y la enfermedad de amor». II CIDAC, pp. 201-224.

El SAFFar, Ruth (1990). «Persiles' Retort: An Alchemical Angle on the Lover's Labors». Cervantes, 10, pp. 17-33.

Forster, Edward Morgan (1983). Aspectos de la novela. Guillermo Lorenzo (trad.). Madrid: Debate.

Fradejas Lebrero, José (1985). Novela corta del siglo xVI. Madrid: Plaza y Janés.

Guillén, Claudio (1988). El primer siglo de Oro: estudios sobre géneros y modelos. Barcelona: Crítica.

Herrero García, Miguel (1966). Ideas de los españoles del siglo XVII. Madrid: Gredos.

Huarte de San Juan, Juan (1989). Examen de ingenios. Guillermo Serés (ed.). Madrid: Cátedra.

Hurtado Torres, Antonio (1983). La prosa de ficción en los siglos de oro. Madrid: Playor.

Johnson, C. B. (1971). «Montemayor's Diana: A Novel Pastoral». Bulletin of Hispanic Studies, 48, pp. 20-35.

Keightley, R. G. (1975). «Narrative Perspectives in Spanish Pastoral Fictions». Journal of the Australian Universities Language and Literature Association, 44, pp. 194-219.

Kristeva, Julia (1974). El texto de la novela. Jordi Llovet (trad.). Barcelona: Lumen.

Libro contra engaños y peligros del mundo (1934). Madrid: Cámara Oficial del Libro de Madrid. 
Libro de los gatos (1950). John Keller (ed.). Madrid: CSIC, Clásicos Hispánicos.

López Pinciano, Alonso (1953). Philosophia antigua poetica. Alfredo Carballo (ed.). Madrid: Marsiega.

Luthi, Max (1947). Das Europäische Volksmärchen. Form und Wesen. Eine literaturwissenschaftliche Darstellung. Bern: A. Francke AG. Verlag.

Manuel, Don Juan (1955). «Libro del Caballero y del Escudero». Obras. José María Castro y Calvo y Martín de Riquer (eds.). Barcelona: CSIC, Clásicos Hispánicos, pp. 7-72.

(2004). El Conde Lucanor. María Jesús Zamora Calvo (ed.). Madrid: Edaf.

Menéndez Pelayo, Marcelino (1961). Orígenes de la novela. Madrid: CSIC.

Montemayor, Jorge de (1954). Los siete libros de la Diana. Francisco López Estrada (ed.). Madrid: Espasa Calpe.

(1991). Los siete libros de la Diana. Asunción Rallo (ed.). Madrid: Cátedra.

(1996). Jorge de Montemayor. Los siete Libros de la Diana. Juan Montero (ed.). Barcelona: Crítica.

Muir, Edwin (1967). The Structure of the Novel. Londres: Hogarth Press.

Palomo, María del Pilar (1976). La novela cortesana. Forma y estructura. Barcelona: Planeta.

Prieto, Antonio (1975). Morfología de la novela: Barcelona: Planeta.

Rico, Francisco (1988). Problemas del Lazarillo. Madrid: Cátedra.

Romero, Carlos (2002). «Introducción, edición, notas y epílogo». Miguel de Cervantes. Los trabajos de Persiles y Sigismunda. Madrid: Cátedra.

Ruiz, Juan (1988). Libro de Buen Amor. José Luis Girón Alconchel (ed.). Madrid: Castalia.

Sánchez Vercial, Clemente (1951). Libro de los exemplos por A.B.C. John Keller (ed.). Madrid: CSIC, Clásicos Hispánicos.

SANTA Cruz, Melchor de (1996). Floresta española. Maximiliano Cabañas (ed.). Madrid: Cátedra.

Soons, Alan C. (1976). Haz y envés del cuento risible en el Siglo de Oro. Londres: Tamesis Books Limited.

SuÁrez Figueroa, Cristóbal (1618). El Pasajero. Barcelona: Gerónimo Margarit.

TACCA, Oscar (1975). Las voces de la novela. Madrid: Gredos.

VALDÉs, Juan de (1972). Diálogo de la lengua. Antonio Comas (ed.). Barcelona: Bruguera.

VeGA, Lope de (1968). «Las fortunas de Diana». Novelas a Marcia Leonarda. Francisco Rico (ed.). Madrid: Alianza Editorial.

(2012). Arcadia, prosas y versos. Antonio Sánchez Jiménez (ed.). Madrid: Cátedra. 


\section{\%}

«... En TIEMPO MENOS DisCRETO QUE El DE AGORA, AUNQUE DE HOMBRES MÁS SABIOS, SE

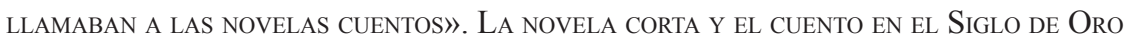

RESUMEN: En este artículo nos proponemos realizar un repaso a la concepción que se tenía de la novela corta y del cuento en el Siglo de Oro español, el origen etimológico de dichas narraciones, cómo fueron utilizadas por los escritores de esa época, cómo surgió el desorden a la hora de nombrarlas y emplearlas, para terminar planteando los rasgos textuales que diferencian a estos dos géneros tan próximos como distintos en la literatura áurea hispánica.

Palabras Clave: Novela corta, Cuento, Literatura del Siglo de Oro español.

«... EN TIEMPO MENOS DISCRETO QUE EL DE AGORA, AUNQUE DE HOMBRES MÁS SABIOS, SE LLAMABAN A LAS NOVELAS CUENTOS». The NOVEL AND the SHORT STORY IN GOLDEN AGE.

ABSTRACT: This article proposes a conceptual review of the novella and the short story in the Spanish Golden Age, the etymological origin of these narrations, how they were used by the writers of that time, the confusion that arose over their nomenclature and utilization, and finally, the textual characteristics that differentiate these two genres that are so similar yet so alike in Golden Age Literature.

Keywords: Novel, Short Story, Spanish Golden Age Literature. 
Evangelina Rodríguez Cuadros (Universitat de València)

Novela cortesana, novela barroca, novela corta: de la incertidumbre al canon .9

Mita Valvassori (Universidad de Los Lagos)

El modelo narrativo del Decamerón en la Edad de Oro: una vieja historia .21

Antonio Gargano (Università degli Studi di Napoli Federico II)

«Difficile est proprie communia dicere»: el género de la novella entre

Boccaccio y Cervantes

Guillermo Carrascón (Università degli Studi di Torino)

Apuntes para un estudio de la presencia de Bandello en la

novela corta del siglo XVII

Leonardo Coppola (Università degli Studi «G. d'Annunzio» di Chieti-Pescara)

La proyección de Straparola en la novela española del Siglo de Oro desde una perspectiva editorial

Mireia Aldomì García

Didactismo, género literario y lector en Giraldi Cinzio.

María Jesús Zamora (Universidad Autónoma de Madrid)

«...En tiempo menos discreto que el de agora, aunque de hombres más sabios, se

Ilamaban a las novelas cuentos». La novela corta y el cuento en el Siglo de Oro.....109

Marcial Rubio (Università degli Studi «G. d'Annunzio» di Chieti-Pescara)

La contribución de Cervantes a la novela barroca: la ejemplaridad. .125

PIERRe Darnis (Université Bordeaux Montaigne)

La fuerza de la sangre, La ilustre fregona $y$ Las dos doncellas: ¿tres tipos

folclóricos?

María Soledad ArRedondo (Universidad Complutense de Madrid)

De La gitanilla $a$ La sabia Flora malsabidilla. El género, el personaje

y el matrimonio

Antonella Gallo (Università degli Studi di Verona)

Fabulaciones en equívocos burlescos: la Chrónica del monstro imaginado (1615)

de Alonso de Ledesma y novela corta barroca

David GonZález Ramírez (Universidad de Málaga)

El filósofo del aldea (1625) de Baltasar Mateo Velázquez: recepción textual

e hipótesis autorial.

Jonathan BRAdBury (University of Exeter)

La narrativa breve en la miscelánea del siglo XVII 
Cristina Castillo Martínez (Universidad de Jaén)

«La fuente del desengaño»: de las Noches de invierno de Eslava a la Tercera

Diana de Tejeda.

María Zerari (Université Paris-Sorbonne, CLEA)

Furor in fabula: La cruel aragonesa de Castillo Solórzano (o de la dama monstruo).. 241

Giulia Giorgi (Università degli Studi di Ferrara)

Alonso de Castillo Solórzano reescritor de sí mismo: algunas notas sobre los

Escarmientos de amor moralizados y el Lisardo enamorado .257

Angela Fabris (Alpen-Adria-Universität Klagenfurt)

El diálogo con el público y los espacios reales y de maravilla en

Casos prodigiosos y cueva encantada de Juan de Piña .267

María Rocío LePe García (IES San Sebastián, Huelva)

La traducción inglesa de Hipólito y Aminta: una adaptación

con fines comerciales 281

Andrea Bresadola (Università degli Studi di Udine)

La novela española en la Italia del siglo XVII: el caso de Il Feniso

de Francisco de Quintana

José Teruel (Universidad Autónoma de Madrid)

El triunfo del Desengaño. Marco y desengaño postrero de la Parte segunda

del Sarao y entretenimiento honesto, de María de Zayas

Nieves Romero-Díaz (Mount Holyoke College)

Lecturas alternativas en la Novela del fin bueno en mal principio

de doña Ana Francisca Abarca de Bolea.

Shifra Armon (University of Florida)

Compromiso y distanciamiento en La Venus de Ferrara

de Mariana de Carvajal Saavedra

Mechthild Albert (Rheinische Friedrich-Wilhelms-Universität Bonn)

Las "noches": un subgénero novelístico en perspectiva comparada.... .365

Fernando Copello Jouanchin (Université du Maine, Le Mans)

El mueble en la novela corta del Siglo de Oro: algunas reflexiones

en torno a la cama

Ilaria Resta (Università del Salento):

De la novella al entremés pasando por la novela corta: reescrituras del cuento

La gara delle tre mogli del Cieco di Ferrara. 


\section{EDAD DE ORO}

Revista de Filología Hispánica XXXIII

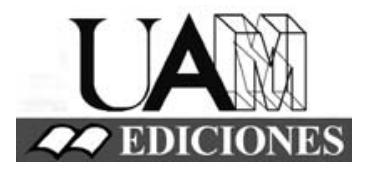




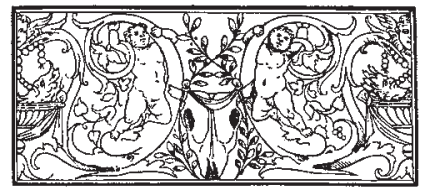

\section{Edad de Oro. Revista de Filología Hispánica}

ISSN: 0212-0429

Dirección:

Teodosio Fernández

Secretaría y edición:

José Ramón Trujillo

Coordinador del volumen XXXIII:

Rafael Bonilla Cerezo

Comité científico internacional:

Carlos Alvar (Univ. de Ginebra)

Ignacio Arellano (Univ. de Navarra)

Javier Blasco (Univ. de Valladolid)

Alberto Blecua (UAB)

Jean Canavaggio (Univ. de París X)

Laura Dolfi (Univ. de Turín)

Aurora Egido (Univ. de Zaragoza)

Víctor García de la Concha (RAE)

Luciano García Lorenzo (CSIC)

Joaquín González Cuenca (Univ. de Castilla-

La Mancha)

Agustín de La Granja (Univ. de Granada)

Begoña López Bueno (Univ. de Sevilla)

Michel Moner (Univ. de Toulouse III)

Joan Oleza (Univ. de Valencia)

Alfonso Rey (Univ. de Santiago)

Lina Rodríguez Cacho (Univ. de Salamanca)

Leonardo Romero Tobar (Univ. de Zaragoza)

Aldo Ruffinatto (Univ. de Turín)

Lía Schwartz (City University of New York)
Redacción y admisión de originales:

Teodosio Fernández

Edad de Oro

Departamento de Filología Española

Universidad Autónoma de Madrid

28049 Madrid (España)

Tfno.: +0034 914974090

correo: teodosio.fernandez@uam.es

Distribución, suscripción y venta:

Servicio de Publicaciones de la UAM

Universidad Autónoma de Madrid

28049 Madrid (España)

Intercambio de publicaciones:

Biblioteca de la Facultad de Filosofía y

Letras (UAM)

Universidad Autónoma de Madrid

28049 Madrid (España)

Han colaborado en este volumen:

Departamento de Filología Española (UAM)

Facultad de Filosofía y Letras (UAM)

Proyecto I+D FFI2013-41264-P La novela

corta del siglo XVII: estudio y edición (y II)

Edad de Oro se recoge en las siguientes bases de datos: SCOPUS, MLA Database, HLAS, Latindex, PIO-Periodical Content Index, ISOC, Dialnet, MIAR, ERIH, DICE, Sumaris CBUC, Ulrich's. Se encuentra evaluada en CIRC: A; INRECH: primer cuartil, posición 6 de 50; MIAR difusión ICDS live: 9.977; SCImago Journal \& Country Rank: H Index 2, SJR 0,101, Q4; RESH índice de impacto: 0.162; ERIH: A INT1; Carhus Plus+: B. 